\title{
Wanting to change the world, is it too much of a good thing? How sustainable orientation shapes entrepreneurial behaviour
}

\author{
Étienne St-Jean, Ph.D. \\ Professor in entrepreneurship \\ Université du Québec à Trois-Rivières \\ Institut de recherche sur les PME \\ 3351, boul. des Forges, CP 500 \\ Trois-Rivières (Québec) \\ CANADA G9A 5H7 \\ Email: etienne.st-jean@uqtr.ca \\ François Labelle, Ph.D. \\ Professor in management \\ Université du Québec à Trois-Rivières \\ Institut de recherche sur les PME \\ 3351, boul. des Forges, CP 500 \\ Trois-Rivières (Québec) \\ CANADA G9A 5H7 \\ Email: francois.labelle@uqtr.ca
}

Keywords: Entrepreneurial behaviour; sustainable orientation; entrepreneurial motivation; Social Cognitive Career Theory; 


\title{
Wanting to change the world, is it too much of a good thing? How sustainable orientation shapes entrepreneurial behaviour
}

\author{
Structured abstract
}

\section{Purpose}

When pursuing a sustainable orientation (SO), entrepreneurs can resolve environmental and social problems and act as change agents by pursuing opportunities related to market failures. While many studies focus on entrepreneurial intention, very few try to explain entrepreneurial behaviour. This paper contributes to this issue by highlighting the circumstances under which people could be led to become sustainable entrepreneurs. It examines the effect of $\mathrm{SO}$, as well as the entrepreneurial motivation to change society as key drivers of entrepreneurial behaviour.

\section{Design}

The hypotheses were tested in three waves (six-month interval) on a sample of 197 university students that are neither entrepreneurs, nor involved in any entrepreneurial processes. We measured entrepreneurial behaviour as a dependent variable and used subjective norms towards entrepreneurship, entrepreneurial self-efficacy, entrepreneurial attitude as well as entrepreneurial motivation and sustainable orientation as independent variables.

\section{Findings}

Contrary to our expectations, sustainability orientation has a negative impact on entrepreneurial action. However, individuals who think that entrepreneurship can change society (instrumentality) exhibit higher entrepreneurial action. Furthermore, this belief positively moderates the negative impact of SO on entrepreneurial action. In other words, if someone thinks that entrepreneurship can change the world, not only he/she is more inclined to engage in entrepreneurial actions but their values of SO will not decrease their entrepreneurial action.

\section{Limitation}

A longer timeframe of longitudinal research is needed to overcome our limitation regarding our assessment of entrepreneurial action.

\section{Practical implication/value}

As a practical implication, educators who want to engage their institution as an engine of change towards sustainable development could highlight cases of sustainable businesses where profits, environmental and social issues were not neglected to improve the perceived feasibility and thus, entrepreneurial action.

\section{Originality/value}

Results demonstrate the negative effect of sustainable orientation on entrepreneurship as a career choice, but not for those who believe that they can change society through this mean. This research highlights the relevance of Socio Cognitive Career Theory in the field of entrepreneurship, especially the neglected effect of outcome expectations on entrepreneurship as a career choice. 


\title{
Wanting to change the world, is it too much of a good thing? How sustainable orientation shapes entrepreneurial behaviour
}

\author{
Structured abstract
}

\section{Purpose}

When pursuing a sustainable orientation (SO), entrepreneurs can resolve environmental and social problems and act as change agents by pursuing opportunities related to market failures. While many studies focus on entrepreneurial intention, very few try to explain entrepreneurial behaviour. This paper contributes to this issue by highlighting the circumstances under which people could be led to become sustainable entrepreneurs. It examines the effect of $\mathrm{SO}$, as well as the entrepreneurial motivation to change society as key drivers of entrepreneurial behaviour.

\section{Design}

The hypotheses were tested in three waves (six-month interval) on a sample of 197 university students that are neither entrepreneurs, nor involved in any entrepreneurial processes. We measured entrepreneurial behaviour as a dependent variable and used subjective norms towards entrepreneurship, entrepreneurial self-efficacy, entrepreneurial attitude as well as entrepreneurial motivation and sustainable orientation as independent variables.

\section{Findings}

Contrary to our expectations, sustainability orientation has a negative impact on entrepreneurial action. However, individuals who think that entrepreneurship can change society (instrumentality) exhibit higher entrepreneurial action. Furthermore, this belief positively moderates the negative impact of SO on entrepreneurial action. In other words, if someone thinks that entrepreneurship can change the world, not only he/she is more inclined to engage in entrepreneurial actions but their values of SO will not decrease their entrepreneurial action.

\section{Limitation}

A longer timeframe of longitudinal research is needed to overcome our limitation regarding our assessment of entrepreneurial action.

\section{Practical implication/value}

As a practical implication, educators who want to engage their institution as an engine of change towards sustainable development could highlight cases of sustainable businesses where profits, environmental and social issues were not neglected to improve the perceived feasibility and thus, entrepreneurial action.

\section{Originality/value}

Results demonstrate the negative effect of sustainable orientation on entrepreneurship as a career choice, but not for those who believe that they can change society through this mean. This research highlights the relevance of Socio Cognitive Career Theory in the field of entrepreneurship, especially the neglected effect of outcome expectations on entrepreneurship as a career choice. 


\section{Wanting to change the world, is it too much of a good thing? How sustainable orientation shapes entrepreneurial behaviour}

\section{Introduction}

Sustainable entrepreneurship is when entrepreneurs pursue a triple bottom line in balancing economic wealth, environmental preservation and social equity (Hooi et al., 2016). This concept gained popularity in recent years, not only in research (e.g. Johnson and Schaltegger, 2016; Perez-Batres et al., 2012) but also in society in general. Indeed, as more and more people join the movement defending sustainability principles, enterprises are expected to follow suit. This is what emerged from the Conference of the Parties (COP21) held in Paris in December 2015, where 195 countries committed to reinforcing the world's answer to the threat of climate change by setting targets and implementing sustainability practices and poverty alleviation measures (United Nations, 2015).

By their key position in society, small and medium-sized enterprises (SME) can fuel the shift towards sustainable development (Schaltegger and Wagner, 2011; York and Venkataraman, 2010). Indeed, they represent more than $95 \%$ of organisations located in developed countries (OCDE, 2005). Consequently, sustainable entrepreneurs, who adhere to these principles and develop sustainable businesses, are the driving force behind this transformation (Pacheco, Dean and Payne, 2010). However, despite the fact that the literature indicates that sustainable entrepreneurs will be crucial in reaching sustainable development goals, there is still little knowledge about the triggers of sustainable entrepreneurship in individuals. This is the main purpose of this study.

Recent works show that activists are those who will most likely want to become sustainable entrepreneurs (Kuckertz and Wagner, 2010). Indeed, as they promote values of 
sustainable development, thus demonstrating high sustainable orientation, it is believed activists may perceive entrepreneurship as a means to apply their values and have a more significant effect on the societal changes close to their hearts. In that respect, these individuals would be interested in pursuing a sustainable opportunity that could lead to the creation of a sustainable enterprise (Spence, Gherib and Biwolé, 2008; Wagner, 2012).

Nevertheless, these pioneering works do not take into account explanatory models of entrepreneurial intention and action to understand the phenomenon, particularly Social Cognitive Career Theory (SCT) (Lent, Brown and Hackett, 2002) which is more explicit than the Theory of Planned Behaviour (TPB) (Ajzen, 1991) on dimensions related to motivation (Vroom, 1964). In that respect, on top of mobilising components of the TPB, this theory adds outcome expectation as an explanatory factor of entrepreneurial action. The founding idea being that if one's sustainable orientation (SO) (valence) is likely to stimulate the intention of becoming an entrepreneur to pursue a sustainable opportunity and put it into action, it will be moderated by one's belief that entrepreneurship is a good way to change the world (instrumentality). This belief allows one to channel one's SO values towards this career choice while those who think businesses and entrepreneurs are at the source of social and environmental problems will prefer to refrain from adopting this path.

The expected contributions of this study are multiple. First, it aims to validate the positive relationship between sustainable orientation and entrepreneurial action in cultural contexts other than Germany and France (Ref: Kuckertz and Wagner, 2010) with the logic of replication and theory consolidation of this promising idea (Berthon et al., 2002). Second, this study serves to validate the relevance of SCT when analysing entrepreneurial 
intention and action, particularly pertaining to dimensions of motivation. Third, this study contributes to the enrichment of the Kuckertz and Wagner model (2010) by proposing a positive moderating effect of the belief that entrepreneurship can change the world on the relationship between SO and entrepreneurial action. Such a conceptualisation, if demonstrated, would allow to better understand the determinants on which one can act to stimulate entrepreneurial intention in those who show sustainable orientation and their action towards business creation. Finally, from an educational and practical point of view, this study contributes to a better knowledge of the determinants of commitment from potential young entrepreneurs by presenting results of an inquiry performed amongst a population of university students. This enables educational institutions to adapt their speeches and training to, on one hand, enhance the development of sustainable orientation in their students and, on the other hand, to implement activities that are likely to reframe the beliefs regarding the benefits entrepreneurship can bring to society. Ultimately, educational institutions are provided with means to participate in the transformation of society by promoting sustainability practices in a more pronounced way.

This article starts by presenting the concept of sustainable orientation and its expected relationship with entrepreneurial action. It continues with the explanation of how SCT components can moderate entrepreneurial action. This is followed by a presentation of the methodology behind an inquiry performed amongst university students. Finally, results are presented and discussed as well as potential contributions and directions for future research.

\section{Sustainability orientation and entrepreneurial intention}


Many researchers suggest that sustainable entrepreneurs may offer potential contributions to the social and environmental problems faced in a perspective of collective welfare (e.g. Cohen and Winn, 2007; Dean and McMullen, 2007; Patzelt and Shepherd, 2011; York and Venkataraman, 2010). Indeed, sustainable entrepreneurs found and develop organisations that reconcile economic, social and environmental objectives to counter the climatic and social upheavals which are, for the most part, a direct consequence of the activities of enterprises (IPCC, 2014).

Values are considered as relatively stable guiding principles in people's life that support their attitudes and behaviours (Becker and Félonneau, 2011; Rokeach, 1973). Therefore, those who hold pro-environmental and pro-social values and choose to become entrepreneurs are likely to become sustainable entrepreneurs. The concept of sustainable orientation (SO) refers to a person's pro-environmental and pro-social values and implies positive attitudes towards the environment and society as well as a strong opposition to behaviours that can alter their state (Corral-Verdugo et al., 2009).

Previous studies have shown that individuals with an elevated SO also have a greater willingness to engage in actions that transform society (Howell, 2013; Stern et al., 1995). Some may do it by founding an enterprise aiming at fulfilling environmental and social needs while others would rather engage in civil action by joining, for example, activist organisations. In both cases, these individuals, thanks to their extensive knowledge base pertaining to the means of achieving sustainability, can identify sustainable opportunities that less engaged individuals cannot perceive (Wagner, 2012). They are also able to get things done more easily. Hence, the relationship between $\mathrm{SO}$ and entrepreneurial action is likely and would help explain the presence of sustainable entrepreneurs, including 
social entrepreneurs, who are a specific category (Seelos and Mair, 2005). In addition, SO is related to the entrepreneurial intention of university students (Kuckertz and Wagner, 2010), which has the potential to drive them towards action (Kautonen, Gelderen and Fink, 2015). Therefore, it is likely that people with a strong sustainable orientation are more inclined to engage in entrepreneurship ${ }^{1}$ :

H1: There is a positive relationship between an individual's sustainable orientation and entrepreneurial action.

\section{Socio Cognitive Career Theory and Motivation Theory}

In a recent meta-analysis, researchers demonstrated that the theories of intention leading to entrepreneurial behaviour benefit in combining together, as natural overlaps exist amongst their underlying concepts (Schlaegel and Koenig, 2014). This recommendation was applied by joining the Theory of Planned Behaviour (TPB) of Ajzen (1991) with the Socio Cognitive Career Theory (SCT) of Lent et al. (2002) to demonstrate the entrepreneurial action of individuals with strong SO. The TPB suggests that before behaviour, intentions are determined through three variables: attitude towards the behaviour (or the career), subjective norms and perceived behavioural control. Also, SCT stipulates that two direct precedents influence intentions and actions towards the career: self-efficacy and outcome expectation. Outcome expectation consists of the valence and the instrumentality towards these "outcomes". SCT partly relies on Vroom's (1964) motivation theory stating that an individual has greater motivation to accomplish a task

\footnotetext{
${ }^{1}$ Just as Kuckertz and Wagner (2010) suggest, the nature of the business to be created is not specified and the presumption is that "if individuals have a high sustainability orientation and plan to become selfemployed, they will usually incorporate sustainability considerations when conceptualizing their ventures". (p. 332).
} 
when the expected results are valued (valence), when the belief that actions will lead to reaching expected results is held (instrumentality), as well as their perceived capability to accomplish said task (expectation, which essentially corresponds to self-efficacy) (Vroom, 1964). As numerous studies mobilising TPB measure the perceived behavioural control through the entrepreneurial self-efficacy (e.g. Engle et al., 2010; St-Jean et al., 2014), combining the two explanatory theories of intention and performance of entrepreneurial action allows to retain five (5) important constructs: attitude towards the career, subjective norms, entrepreneurial self-efficacy, valence and instrumentality of expected results (outcome expectation).

Specifically, it may be proposed that an individual who believes entrepreneurship will help attain their goals (instrumentality) related to their values (valence) would be strongly motivated by this career (Lent et al., 2002). In the context examined today, individuals with strong sustainable orientation (valence) should want to become entrepreneurs even more and carry out this action if they believe entrepreneurship will allow them to improve society on both social and environmental levels (instrumentality).

Considering that sustainability orientation is a hot topic and that society adheres to the values it promotes (i.e. respect for the environment) as well as younger individuals are particularly concerned about this matter (Kuckertz and Wagner, 2010), it is highly probable that the belief that entrepreneurship can change the world (instrumentality) could motivate students to take action towards this career. Bearing in mind the attractiveness of an entrepreneurial career among young individuals in Quebec (St-Jean and Duhamel, 2016), the belief that this career will improve society could be a stimulus fostering behaviours of entrepreneurial action. Consequently, the following hypothesis is formulated: 
$\mathrm{H} 2$ : The belief that entrepreneurship can change the world (instrumentality) is linked to entrepreneurial action.

According to Vroom (1964), the combined effect of valence and instrumentality (which consists of an outcome expectation) will be the source of motivation and lead to the behaviour. Therefore, the belief that entrepreneurship can improve society both socially and environmentally (instrumentality) should mitigate the effect of sustainable orientation on the performance of entrepreneurial action. Indeed if an individual believes that the world can be changed through entrepreneurship, he/she will be more inclined to take action towards this choice. Thus, those who possess a high sustainable orientation and believe that entrepreneurship can change the world could perform entrepreneurial behaviour more than those who believe entrepreneurship is not an effective way of doing so. In this latter case, they will perform actions outside of entrepreneurship. Considering this reasoning, a third hypothesis is proposed:

H3: The belief that entrepreneurship can change the world (instrumentality) interacts with sustainable orientation (valence) to improve the performance of entrepreneurial action in a way that the greater the instrumentality is, the stronger the effect on entrepreneurial action.

\section{Methodology}

Research sample

This research sample comes from a one-year comprehensive longitudinal research on the entrepreneurial career conducted amongst Quebec university students (Canada). The sample that responded to the three (3) stages (a six-month interval between each collection) corresponds to 623 individuals. Since the intent of this research aims at understanding entrepreneurial behaviour, students who had previously owned an enterprise, currently own 
one or were in a start-up process during the initial phase of collection (T0) were removed. This left 293 individuals who participated in all three phases of the collection.

Given the longitudinal character of the research, some questions were asked during the initial phase of the data collection, for example, age, gender, subjective norms, attitudes towards entrepreneurial tasks and self-efficacy or the fact of having attended entrepreneurship university classes. Sustainable orientation was posed at a 6-month interval with the initial collection (T1) and the performance of entrepreneurial action was asked one (1) year following the initial collection (T2). Although attitudes can change over time, the study supposed that, on one hand, they are stable enough over a period of six (6) months and, on the other hand, this allows to reduce the risks associated with the common method bias (Podsakoff et al., 2003). The sample on which are based the subsequent analyses comprises 197 students who answered all the questions asked to confirm the hypotheses made ${ }^{2}$.

\section{Measures}

\section{Dependent variable}

To measure entrepreneurial action, a tool developed by Thompson (2009) was used. This tool measures behaviours that demonstrate a strong commitment towards business start-up, including items such as 'Spend time learning about starting a firm', 'Never search for business start-up opportunities' (reversed item) or 'Are saving money to start a business'. As the questionnaire was administered in French, every measure was translated from English to French by two fully bilingual researchers. Inconsistencies were

\footnotetext{
2 The regressions were calculated by removing all the cases, including one question skipped by the respondent.
} 
resolved through a third translation. The Likert scale ranges from 1 - I strongly disagree to 7 - I strongly agree. The measure is one-dimensional $(57.09 \%$ of the variance explained by a single factor) and has a Cronbach's alpha of 0.849 . The average score was used for subsequent analyses.

\section{Independent variables}

Entrepreneurial self-efficacy was measured using 20 items proposed by McGee et al. (2009). The items measure the level of confidence in the respondents' ability to accomplish certain specific tasks as suggested by Bandura (1997). For this study, the tasks described were entrepreneurial tasks. Items covered the expected tasks related to an entrepreneurial career, including statements such as 'Identify the need for a new product or service', 'Get others to identify with and believe in my vision and plans for a new business' and 'Manage the financial assets of my business'. The scale ranged from $0 \%$ to $100 \%$, by steps of $10 \%$, depending on the perception of personal efficacy of the individual towards those questions. The Cronbach's alpha represents 0.921 . The average score of all twenty items was used for this research.

Subjective norms regarding an entrepreneurial career were measured using the tool developed by Kolvereid and Isaksen (2006), comprised of two (2) series of six (6) items. First, respondents are asked to rate the opinion of six (6) groups of individuals regarding an entrepreneurial career: parents, spouse (if applicable), brothers/sisters (if applicable), family, close friends and acquaintances, with a scale ranging from $-3=$ extremely negative opinion to $+3=$ extremely positive opinion (and $0=$ neutral). Then, respondents are asked to rate the importance attached to the opinion of these people about 
their choice of employment status, with a scale ranging from 1 - Not at all important to 7 - Extremely important. The opinion of each group of people was then multiplied by the importance given by the respondent, creating a score of subjective norms varying from -21 to +21 for each of the six groups of people. The Cronbach's alpha for these six (6) items represents $0.801 .$. The average score of the items was used for this research.

Attitude towards entrepreneurship was measured by asking respondents to rate their interest in the five main duties of an entrepreneur (McGee et al., 2009): 1 - Identify a new product/service, 2 - Plan the development and marketing of new products/services, 3 - Explain and convince others of one's vision or of one's business project, 4 - Recruit, train and manage employees and 5 - Manage, organize and interpret financial statements. Respondents use a scale ranging from 1 - Not at all interested, to 5 - Extremely interested. The Cronbach's alpha for these five (5) items represents 0.785 . The average score of the items was used for this research.

Sustainable orientation (SO) was measured using six (6) items proposed by Kuckertz and Wagner (2010). They include statements such as 'I think that environmental problems are one of the biggest challenges for our society' and 'I think that entrepreneurs and companies need to take on a larger social responsibility'. The scale ranges from 1 - I strongly disagree to 7 - I strongly agree. The Cronbach's alpha for these six (6) items represents 0.786 . The average score of the items was used for this research.

Instrumentality of entrepreneurship to change the world rests in a simple question to verify if the respondent believes entrepreneurship allows social improvements such as having a fair and balanced society, improves people's autonomy and dignity, reduces 
suffering, etc. The item was measured on a Likert scale ranging from 1 - Not at all to 5 - Extremely.

\section{Moderating variable}

A score for the interaction variable between sustainable orientation and instrumentality of entrepreneurship to change the world was calculated. First, each variable of this study was centered to the mean. This procedure facilitates the interpretation of the interaction result. Second, the two variables were multiplied together.

\section{Control variables}

Certain variables are known to influence the intention to become an entrepreneur and, consequently, must be used as control variables (Spector and Brannick, 2011). Gender (Shinnar, Giacomin and Janssen, 2012) and age (Kautonen, Luoto and Tornikoski, 2010) were used as control variables.

\section{Procedure}

The different variables and their correlations were first analysed to detect potential problems. Figure 1 shows the mean, standard deviation and correlation for each variable. No potential problem of multi-collinearity was detected. In addition, VIF indexes are well below the acceptable threshold of 10.0, which suggests usable data for hierarchical linear regressions.

Hierarchical linear regressions were conducted by first entering the control variables (model 1), then the variables of the Theory of Planned Behaviour (model 2), followed by sustainable orientation (model 3), to test hypothesis 1. Entrepreneurship instrumentality to change the world was then added (model 4), followed by the interaction 
between this variable and sustainable orientation (model 5). All cases with missing data for at least one question were removed, thus reducing the sample to 197 individuals.

Table 1. Mean, standard deviation and correlation between variables

\begin{tabular}{lrrrrrrrrrr}
\hline & Mean & S.D. & 1 & 2 & 3 & 4 & 5 & 6 & 7 & 8 \\
\hline 1-Entrepreneurial Action & 3.16 & 1.35 & 1.00 & & & & & & & \\
2-Gender & 0.61 & 0.49 & -0.29 & 1.00 & & & & & & \\
3-Age & 24.78 & 5.27 & 0.07 & 0.04 & 1.00 & & & & & \\
4-Subjective Norms & 6.94 & 5.02 & 0.29 & 0.00 & 0.08 & 1.00 & & & & \\
5-Entrepr. Self-Efficacy & 6.04 & 1.69 & 0.50 & -0.17 & 0.08 & 0.29 & 1.00 & & & \\
6-Entrepreneurial Attitude & 2.92 & 0.92 & 0.60 & -0.21 & 0.08 & 0.36 & 0.60 & 1.00 & & \\
7-Sustainable Orientation & 5.68 & 0.89 & -0.10 & 0.10 & 0.06 & 0.07 & 0.10 & 0.00 & 1.00 & \\
8-Instrumentality of Entr. & 3.25 & 0.80 & 0.26 & -0.09 & 0.05 & 0.11 & 0.17 & 0.23 & 0.13 & 1.00 \\
\hline Correlations $\geq 0.126=p \leq 0.05$ & & & & & & & & & &
\end{tabular}

\section{Results}

Table 2 shows the results of the analysis. It can be noted being a woman corresponds to a lower level of entrepreneurial action $(p=0.003)$. Age is not significant to explain action $(p=0.279)$ in the final model, but it is significant in model 1 , where only the control variables appear $(p=0.020)$. Model 2 confirms the undeniable contribution of the Theory of Planned Behaviour (TPB) in explaining entrepreneurial action $\left(\Delta \operatorname{adj} \cdot R^{2}=0.32\right)$, where attitudes $(p=0.000)$ and entrepreneurial self-efficacy $(p=0.002)$ are strongly significant to explain it, while subjective norms are not $(p=0.194)$. In Model 3 , the negative effect of sustainable orientation ( $\mathrm{SO}$ ) on entrepreneurial action $(p=0.029)$ is noticed, which is opposite to the expected relationship. Thus, the higher sustainable orientation is, the less individuals place themselves in entrepreneurial action. Hypothesis 1 must then be rejected. Model 4 shows that instrumentality of entrepreneurship to change the world is significant and positive to explain entrepreneurial action, a situation that can 
also be noticed in model 5, which confirms H2. In Model 5, instrumentality has a positive moderating effect $(p=0.021)$ on the relationship between sustainable orientation and entrepreneurial action, which confirms H3.

Table 2. Linear regression of entrepreneurial action

\begin{tabular}{|c|c|c|c|c|c|}
\hline & $\begin{array}{c}\text { Model } 1 \\
\text { Std } \beta \\
\end{array}$ & $\begin{array}{c}\text { Model } 2 \\
\text { Std } \beta \\
\end{array}$ & $\begin{array}{c}\text { Model } 3 \\
\text { Std } \beta \\
\end{array}$ & $\begin{array}{c}\text { Model } 4 \\
\text { Std } \beta \\
\end{array}$ & $\begin{array}{c}\text { Model } 5 \\
\text { Std } \beta \\
\end{array}$ \\
\hline Gender $^{\mathrm{a}}$ & $-0.332^{* * *}$ & $-0.188 * * *$ & $-0.170 * *$ & $-0.160 * *$ & $-0.167^{* *}$ \\
\hline Age & $0.159^{*}$ & 0.075 & 0.067 & 0.060 & 0.058 \\
\hline Subjective Norms & & 0.076 & 0.075 & 0.071 & 0.067 \\
\hline Entr. Self-Efficacy & & $0.216^{* *}$ & $0.243^{* * *}$ & $0.239^{* * *}$ & $0.248^{* * *}$ \\
\hline Entrepreneurial Attitude & & $0.401^{* * *}$ & $0.387^{* * *}$ & $0.368^{* * *}$ & $0.368^{* * *}$ \\
\hline Sustainable Orientation & & & $-0.121^{*}$ & $-0.141^{*}$ & $-0.129 *$ \\
\hline Instrumentality of Entr. & & & & $0.126^{*}$ & $0.117^{*}$ \\
\hline SO X Instrumentality & & & & & $0.089 \dagger$ \\
\hline Adj. $R^{2}$ & 0.115 & 0.435 & 0.446 & 0.458 & 0.463 \\
\hline$\Delta$ sig. & 0.000 & 0.000 & 0.029 & 0.022 & 0.095 \\
\hline $\mathrm{N}$ & 197 & 197 & 197 & 197 & 197 \\
\hline
\end{tabular}

${ }^{\mathrm{a}}$ Men $=0$; Women $=1$

$\dagger=p \leq 0.10 \quad *=p \leq 0.05 \quad * *=p \leq 0.01 \quad * * *=p \leq 0.001$

Figure 1 illustrates the moderating effect of instrumentality to change the world through entrepreneurship on the relationship between sustainable orientation and entrepreneurial action.. The analysis shows that the level of entrepreneurial action of those who are lightly oriented towards sustainability is equivalent for strong or weak instrumentality. Thus, believing that entrepreneurship can change or not change the world places people into a similar action level when they are lightly oriented towards sustainability. However, when they hold strong sustainable values and they believe entrepreneurship cannot contribute to change the world, the action level is lower than those who believe so. As for the latter, their entrepreneurial level of action remains stable and similar compared to those who have a weak sustainable orientation. 


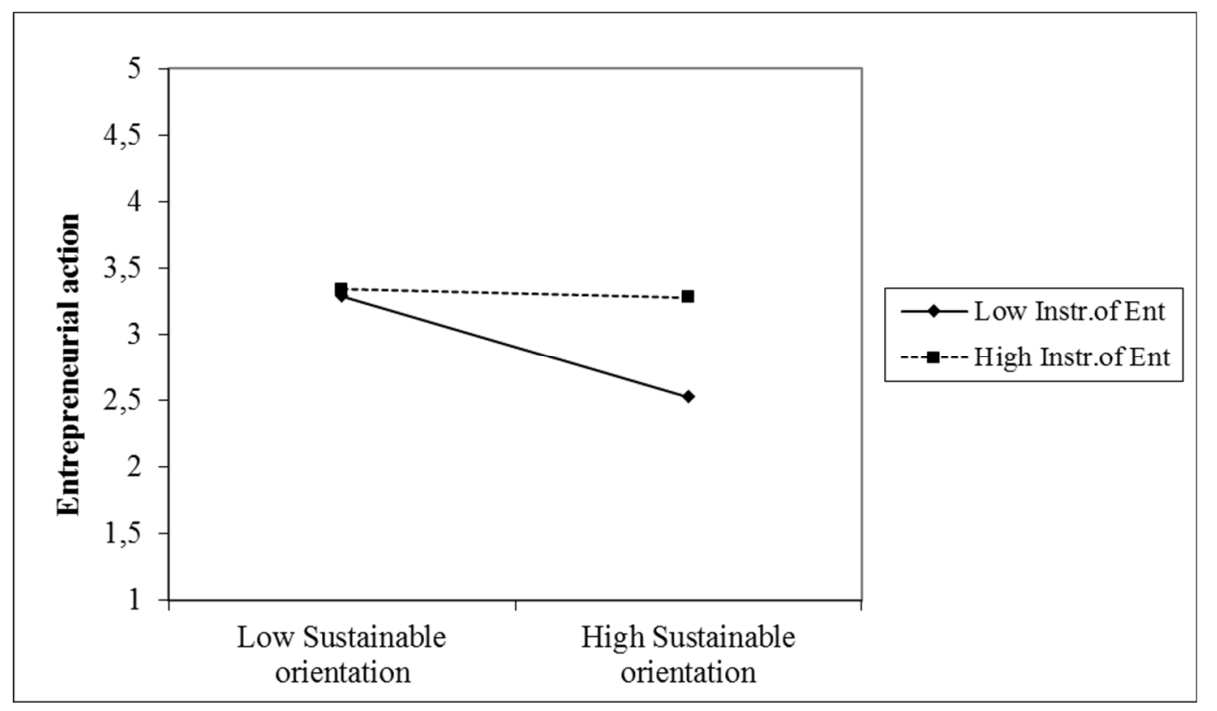

Figure 1. Moderating Effect of Instrumentality to Change the World with Entrepreneurship

\section{Discussion}

The goal of this research was to discover if an individual's sustainable orientation could increase the likelihood of working towards an entrepreneurial career. Contrarily to what Kuckertz and Wagner (2010) found amongst a sample of students, that is a positive relation between the sustainable orientation and the intention to become an entrepreneur, this study shows the exact opposite. In fact, there is a negative and significant relationship between sustainable orientation and entrepreneurial action. Although surprising at first glance, this result can be explained by a probably different conception from the potential benefit of entrepreneurship to promote sustainable development in the mind of Quebeckers. It is possible that in the mind of our sample of students, entrepreneurs are perceived as being more the cause of environmental problems rather than the solution. It is also possible that the cultural perspective plays a role in this important difference. Indeed, Kuckertz and Wagner (2010) hired French students from Alsace and others from Germany. Researches that focus on student entrepreneurial intention show that motivations to become an 
entrepreneur vary considerably depending on the country (Pruett et al., 2009). When one looks at the cultural differences between Germany and Canada according to the Hofstede $(1984)^{3}$ dimensions, it can be noticed that the main difference between the two cultures refers to long-term perspectives in which Germans will invest more in focusing on long term actions while Canadians will hope for much faster results. Thereupon, a society transformed by entrepreneurship may take much longer compared to activism, or even in the involvement in jobs related to sustainable orientation values, where results happen faster. It is therefore possible that, as far as Canadian students are concerned, entrepreneurship is not perceived to be an interesting solution to those oriented towards sustainability. It suggests to pay attention to the instrumentality of entrepreneurship on one hand and to compare it amongst different cultures on the other.

In a replication perspective, this research nuances preceding studies done by Kuckertz et Wagner (2010). The results suggest to pursue the investigation on the relationship between SO and entrepreneurial career for a better understanding of the cultural contexts in which the individuals oriented towards sustainability will be willing to engage in such a career to transform society. Sometimes this relationship appears positive, sometimes negative, raising the question of the moderators that could explain this situation, other than cultural differences. Could it be caused by role models at local or national level that show engagement towards sustainability? Could it be that certain territories have more business opportunities related to sustainability (Wagner, 2012)? Or that certain trainings allow for better identification of them, for instance in the engineering field (Kuckertz and

${ }^{3}$ http://geert-hofstede.com/canada.html 
Wagner, 2010)? For now, these are only work hypotheses that should be tested in the future to identify the potential moderating variables of that process.

Another contribution of this research is in demonstrating that as far as university students are concerned, at least in Canada, the belief that entrepreneurship can change the world (instrumentality) brings them to take actions towards this career. From a theoretical point of view, this result allows to emphasize the relevance of the Social Cognitive Career Theory (SCT) (Lent et al., 2002) to explain the choice of an entrepreneurial career. Indeed, SCT highlights the importance of instrumentality, combined with valence, which constitutes outcome expectations, bringing the career choosing intentions and the steps to reach this objective. Contrary to the Theory of Planned Behaviour, which excludes instrumentality and is limited to attitudes and self-efficacy (in addition to subjective norms), SCT adds a dimension that appears useful to explain entrepreneurial behaviour demonstrated by our results. In addition, this confirms the empirical results obtained by the meta-analysis performed on entrepreneur intention, which showed that models and theories gain by being combined to increase the explanatory power (Schlaegel and Koenig, 2014). SCT also suggests the effect of learning in influencing outcomes expectation, as well as self-efficacy, which allows a reconsideration of the works on entrepreneurial intention as well as entrepreneurial behaviour. The results presented here point in that direction and encourage the pursuit of studies in entrepreneurial career using SCT.

One of the major results of this research is the positive moderating effect of instrumentality on the relationship between sustainable orientation and entrepreneurial action. As demonstrated, the belief that entrepreneurship can improve society neutralizes the negative effect of sustainable orientation on entrepreneurial behaviours. Therefore, the 
effect of a belief related to instrumentality (Vroom, 1964) that is combined with valence (sustainable orientation) to form an outcome expectation toward sustainability, which represents a necessary motivation in leading to behaviour. This confirms the relevance of assessing the entrepreneurial motivation by combining the effects of instrumentality and valence (Vroom, 1964) within SCT (Lent et al., 2002). Those results contribute to reframe the works done on the motivation of becoming an entrepreneur, which are generally limited to the reasons motivating a person to start up a business (e.g. Carsrud and Brännback, 2011; Kirkwood and Walton, 2010; Segal, Borgia and Schoenfeld, 2005). Therefore, it would be useful to better understand the values associated to the entrepreneurial career choice as well as the beliefs associated to the instrumentality of becoming an entrepreneur. Furthermore, these beliefs, as well as the values, can change over time, despite the fact that they are quite stable. It is then possible to imagine that trainings could modify beliefs and values and, therefore, stimulate the motivation of becoming an entrepreneur. It is also probable that the somewhat realistic beliefs regarding an entrepreneurial career could change during the business creation process and after entering the career. For instance, an entrepreneur could believe that entrepreneurship would bring a lot of freedom and flexibility in schedule management, but the precarious situation of the first years may not allow freedom and flexibility, thus adjusting the instrumentality and, consequently, the motivation.

\section{Conclusion}

In order to reach sustainability, our societies need more entrepreneurs who exhibit sustainable orientation. This paper contributes in showing how people with high sustainable orientation can consider entrepreneurship as a career choice and start actions towards this goal. Through Social Cognitive Career Theory (SCT) theoretical lens (Lent et 
al., 2002), the aim was to investigate the effect of outcome expectations to bring motivation in order for an individual to take action to become an entrepreneur. A sample of 197 university students was used throughout a longitudinal design study.

The results show that the belief of instrumentality of entrepreneurship to change the world and sustainable orientation as a value together improve the motivation towards becoming an entrepreneur. In fact, the analysis shows that sustainable orientation reduces the willingness to become entrepreneur and lessen the actions towards this choice. However, the belief that entrepreneurship is a good way to change society (instrumentality) mitigates the negative effect of sustainable orientation on entrepreneurship as a career choice.

This study contributes in showing the relevance of SCT in the field of entrepreneurship, especially the neglected effect of outcome expectations on entrepreneurship as a career choice. The results demonstrate the negative effect of sustainable orientation on entrepreneurship as a career choice, but not on those who believe that they can change society through this mean. Thus, if someone thinks that entrepreneurship can change the world, not only he/she will be more inclined to take actions towards entrepreneurship but their values of SO will not decrease their entrepreneurial action.

Future studies need a longer timeframe of longitudinal research to overcome this study's limitation regarding our assessment of entrepreneurial action. Starting a sustainable business could be perceived as demanding, for a triple bottom line would appear complicated to obtain. As a practical implication, entrepreneurship university courses could address social and sustainable entrepreneurship to illustrate that it might improve 
society. Consequently, this will have a direct effect on the performance of entrepreneurship action, but also a moderating effect that will drive those most activists to consider this career as a possibility. More generally, universities could organize lectures given by sustainable entrepreneurs. It would be a positive way to intervene. Globally speaking, information sessions organised by several organisations offering start-up support could also talk about the dimensions related to the instrumentality of an entrepreneurial career, which could have a beneficial effect on the motivation and, consequently, on performance.

\section{References}

Ajzen, I. (1991), "The theory of planned behavior", Organizational Behavior and Human Decision Processes, Vol. 50 No. 2, pp. 179-211.

Bandura, A. (1997), Self-efficacy : the exercise of control, W.H. Freeman, New York.

Becker, M. and Félonneau, M.-L. (2011), "Pourquoi être pro-environnemental? Une approche socionormative des liens entre valeurs et «pro-environnementalisme»", Pratiques psychologiques, Vol. 17 No. 3, pp. 237-250.

Berthon, P., Pitt, L., Ewing, M. and Carr, C.L. (2002), "Potential research space in MIS: A framework for envisioning and evaluating research replication, extension, and generation", Information Systems Research, Vol. 13 No. 4, pp. 416-427.

Carsrud, A. and Brännback, M. (2011), "Entrepreneurial motivations: what do we still need to know?", Journal of Small Business Management, Vol. 49 No. 1, pp. 9-26.

Cohen, B. and Winn, M.I. (2007), "Market imperfections, opportunity and sustainable entrepreneurship", Journal of Business Venturing, Vol. 22 No. 1, pp. 29-49.

Corral-Verdugo, V., Bonnes, M., Tapia-Fonllem, C., Fraijo-Sing, B., Frías-Armenta, M. and Carrus, G. (2009), "Correlates of pro-sustainability orientation: The affinity towards diversity", Journal of Environmental Psychology, Vol. 29 No. 1, pp. 3443.

Dean, T.J. and McMullen, J.S. (2007), "Toward a theory of sustainable entrepreneurship: Reducing environmental degradation through entrepreneurial action", Journal of Business Venturing, Vol. 22 No. 1, pp. 50-76.

Engle, R.L., Dimitriadi, N., Gavidia, J.V., Schlaegel, C., Delanoe, S., Alvarado, I., He, X., Buame, S. and Wolff, B. (2010), "Entrepreneurial intent: A twelve country evaluation of Ajzen's model of planned behavior", International Journal of Entrepreneurial Behaviour \& Research, Vol. 16 No. 1, pp. 35-57.

Hofstede, G. (1984), Culture's consequences: International differences in work-related values, SAGE Publications, Newbury Park, CA.

Hooi, H.C., Ahmad, N.H., Amran, A., Rahman, S.A., Sarkis, J. and Sarkis, J. (2016), "The functional role of entrepreneurial orientation and entrepreneurial bricolage in 
ensuring sustainable entrepreneurship", Management Research Review, Vol. 39 No. 12, pp. 1616-1638.

Howell, R.A. (2013), "It's not (just)“the environment, stupid!" Values, motivations, and routes to engagement of people adopting lower-carbon lifestyles", Global Environmental Change, Vol. 23 No. 1, pp. 281-290.

IPCC (2014), "Summary for policymakers", in C. B. Field, V. R. Barros, D. J. Dokken, K. J. Mach, M. D. Mastrandrea, T. E. Bilir, M. Chatterjee, K. L. Ebi, Y. O. Estrada, R. C. Genova, B. Girma, E. S. Kissel, A. N. Levy, S. MacCracken, P. R. Mastrandrea \& L. L. White (Eds.), Climate Change 2014: Impacts, Adaptation, and Vulnerability. Part A: Global and Sectoral Aspets, Contribution of Working Group II to the Fifth Assessment Report of the Intergovernemental Panel on Climate Change New-York, NY, Cambridge University Press, pp. 1-32.

Johnson, M.P. and Schaltegger, S. (2016), "Two Decades of Sustainability Management Tools for SMEs: How Far Have We Come?", Journal of Small Business Management, Vol. 54 No. 2, pp. 481-505.

Kautonen, T., Gelderen, M. and Fink, M. (2015), "Robustness of the theory of planned behavior in predicting entrepreneurial intentions and actions", Entrepreneurship Theory and Practice, Vol. 39 No. 3, pp. 655-674.

Kautonen, T., Luoto, S. and Tornikoski, E.T. (2010), "Influence of work history on entrepreneurial intentions in 'prime age'and 'third age': A preliminary study", International Small Business Journal, Vol. 28 No. 6, pp. 583-601.

Kirkwood, J. and Walton, S. (2010), "What motivates ecopreneurs to start businesses?", International Journal of Entrepreneurial Behavior \& Research, Vol. 16 No. 3, pp. 204-228.

Kolvereid, L. and Isaksen, E. (2006), "New business start-up and subsequent entry into self-employment", Journal of Business Venturing, Vol. 21 No. 6, pp. 866-885.

Kuckertz, A. and Wagner, M. (2010), "The influence of sustainability orientation on entrepreneurial intentions - Investigating the role of business experience", Journal of Business Venturing, Vol. 25 No. 5, pp. 524-539.

Lent, R.W., Brown, S.D. and Hackett, G. (2002), "Social cognitive career theory", in D. Brown (Ed.), Career choice and development $4^{\text {th }}$ ed., San-Francisco, USA, JosseyBass, pp. 255-311.

McGee, J., Peterson, M., Mueller, S. and Sequeira, J. (2009), "Entrepreneurial Self Efficacy: Refining the Measure", Entrepreneurship Theory and Practice, Vol. 33 No. 4, pp. 965-988.

OCDE (2005) 'Perspectives de l'OCDE sur les PME et l'entrepreneuriat', Organisation de Coopération et de Développment Économiques (OCDE), Paris.

Pacheco, D.F., Dean, T.J. and Payne, D.S. (2010), "Escaping the green prison: Entrepreneurship and the creation of opportunities for sustainable development", Journal of Business Venturing, Vol. 25 No. 5, pp. 464-480.

Patzelt, H. and Shepherd, D.A. (2011), "Recognizing Opportunities for Sustainable Development", Entrepreneurship Theory and Practice, Vol. 35 No. 4, pp. 631-652.

Perez-Batres, A.P.L.A., Miller, V.V., Pisani, M.J., Henriques, I. and Renau-Sepulveda, G.A.J.A. (2012), "Why do firms engage in national sustainability programs and transparent sustainability reporting?", Management international review, Vol. 52 No. 1, pp. 107-136. 
Podsakoff, P.M., MacKenzie, S.B., Lee, J.Y. and Podsakoff, N.P. (2003), "Common method biases in behavioral research: A critical review of the literature and recommended remedies", Journal of Applied Psychology, Vol. 88 No. 5, pp. 879903.

Pruett, M., Shinnar, R., Toney, B., Llopis, F. and Fox, J. (2009), "Explaining entrepreneurial intentions of university students: a cross-cultural study", International Journal of Entrepreneurial Behaviour \& Research, Vol. 15 No. 6, pp. 571-594.

Rokeach, M. (1973), The nature of human values, The Free Press, New-York.

Schaltegger, S. and Wagner, M. (2011), "Sustainable entrepreneurship and sustainability innovation: categories and interactions", Business Strategy and the Environment, Vol. 20 No. 4, pp. 222-237.

Schlaegel, C. and Koenig, M. (2014), "Determinants of Entrepreneurial Intent: A MetaAnalytic Test and Integration of Competing Models", Entrepreneurship Theory and Practice, Vol. 38 No. 2, pp. 291-332.

Seelos, C. and Mair, J. (2005), "Entrepreneurs in service of the poor: Models for business contributions to sustainable development", Business Horizons, Vol. 48 No. 3, pp. 241-246.

Segal, G., Borgia, D. and Schoenfeld, J. (2005), "The motivation to become an entrepreneur", International Journal of Entrepreneurial Behaviour \& Research, Vol. 11 No. 1, pp. 42-57.

Shinnar, R.S., Giacomin, O. and Janssen, F. (2012), "Entrepreneurial perceptions and intentions: The role of gender and culture", Entrepreneurship Theory and Practice, Vol. 36 No. 3, pp. 465-493.

Spector, P.E. and Brannick, M.T. (2011), "Methodological urban legends: The misuse of statistical control variables", Organizational Research Methods, Vol. 14 No. 2, pp. 287-305.

Spence, M., Gherib, J. and Biwolé, V.O. (2008), "A framework of SMEs' strategic involvement in sustainable development", in R. Wüstenhagen, J. Hamschmidt, S. Sharma \& M. Starik (Eds.), Sustainable Innovation and Entrepreneurship Northampton, MA, Edward Elgar, pp. 49-70.

St-Jean, E. and Duhamel, M. (2016) 'Situation de l'activité entrepreneuriale québécoise : rapport 2015 du Global Entrepreneurship Monitor', Institut de recherche sur les PME, Trois-Rivières (Canada).

St-Jean, E., Nafa, A., Tremblay, M., Janssen, F., Baronet, J. and Loué, C. (2014), "Entrepreneurial intentions of university students: an international comparison between African, European and Canadian students", International Journal of Entrepreneurship and Innovation Management, Vol. 18 No. 2/3, pp. 95-114.

Stern, P.C., Kalof, L., Dietz, T. and Guagnano, G.A. (1995), "Values, beliefs, and proenvironmental action: attitude formation toward emergent attitude objects", Journal of Applied Social Psychology, Vol. 25 No. 18, pp. 1611-1636.

Thompson, E. (2009), "Individual entrepreneurial intent: construct clarification and development of an internationally reliable metric", Entrepreneurship Theory and Practice, Vol. 33 No. 3, pp. 669-694.

United Nations (2015) 'Convention-cadre sur les changements climatiques: Accord de Paris', United Nations, Paris, France. 
Vroom, V.H. (1964), Work and motivation, Wiley, New-York.

Wagner, M. (2012), "Ventures for the public good and entrepreneurial intentions: An empirical analysis of sustainability orientation as a determining factor", Journal of Small Business \& Entrepreneurship, Vol. 25 No. 4, pp. 519-531.

York, J.G. and Venkataraman, S. (2010), "The entrepreneur-environment nexus: Uncertainty, innovation, and allocation", Journal of Business Venturing, Vol. 25 No. 5, pp. 449-463. 